\title{
Development and Validation of Newer High Performance Thin Layer Chromatographic Method for Quantification of Eflornithine Hydrochloride in Pharmaceutical Formulations
}

\author{
Amit Kumar1, Vijender Singh², Praveen Kumar, \\ ${ }^{1}$ Department of Pharmaceutical analysis, NKBR College of Pharmacy \& Research Centre, Meerut, India \\ ${ }^{2}$ Department of Pharmaceutical analysis, BBS Institute of Pharmaceutical \& Allied Sciences, Greater Noida, India \\ ${ }^{3}$ Department of Pharmaceutical Chemistry, S. D. College of Pharmacy and Vocational Studies, Muzaffarnagar, India \\ *Corresponding author: praveensha77@gmail.com
}

Received Mayh 05, 2013; Revised May 19, 2013; Accepted May 20, 2013

\begin{abstract}
A new, simple, sensitive, precise and robust high performance thin layer chromatography (HPTLC) method was developed for the estimation of eflornithine hydrochloride (DFMO) in pharmaceutical dosage forms. Estimation was performed on TLC aluminum plates precoated with silica gel $60 \mathrm{~F}_{254}$ as stationary phase. Linear ascending development was carried out in twin trough glass chamber saturated with mobile phase consisting of methanol: chloroform: acetic acid: $1 \%$ triethylamine $(4: 6: 0.1: 0.5 \mathrm{v} / \mathrm{v} / \mathrm{v})$ at room temperature $\left(25 \pm 2^{\circ} \mathrm{C}\right)$. Analysis of the plate in absorbance mode at 220nm was carried out. The system was found to give compact spots for DFMO with $\mathrm{R}_{\mathrm{f}}$ (Retardation factor) value of 0.55 respectively. The data for calibration plots showed good linear relationship with correlation coefficient of 0.999 in the concentration range of $300-800 \mathrm{ng} \mathrm{mL}^{-1}$ for DFMO respectively. The values of limit of detection (LOD) were $0.6238 \mathrm{ng} \mathrm{mL}^{-1}$ and limit of quantification (LOQ) were $1.8903 \mathrm{ng} \mathrm{mL}^{-1}$ for DFMO respectively. The accuracy of the method was $100.44 \%$. The precision demonstrated a relative standard deviation of less than $2.5 \%$. The results were satisfactory when compared with the literature. This new method was validated according to the International Conference on Harmonization (ICH) guidelines which include linearity, precision, accuracy, specificity, robustness, detection and quantitation limits. The developed methods found to be sufficiently precise and reproducible for established conditions and after validation may be used for routine analysis of eflornithine hydrochloride in pharmaceutical formulations.
\end{abstract}

Keywords: eflornithine hydrochloride (DFMO), quantification, validation, ICH guidelines, HPTLC

\section{Introduction}

Eflornithine (2-fluoromethyl-DL-ornithine; MDL 71782A; DFMO) is a selective, irreversible inhibitor of ornithine decarboxylase enzyme, one of the key enzymes in the polyamine biosynthetic pathway [1,2]. The drug was originally developed for use in cancer, and is in phase III clinical trials for its use in preventing recurrence of superficial bladder cancer. It has been used as antiprotozoal agent in the treatment of meningoencephalic stage of trypanosomiasis caused by Trypanosoma brucei gambienze (African trypanosomiasis) [3,4,5]. It is now licensed for use in sleeping sickness in the USA, Europe and twelve African countries [6]. The drug was originally developed for use in cancer, and is in phase III clinical trials for its use in preventing recurrence of superficial bladder cancer. It has been used as antiprotozoal agent in the treatment of meningoencephalic stage of trypanosomiasis caused by Trypanosoma brucei gambienze (African trypanosomiasis) $[7,8]$. DFMO currently is in development and testing for its anti inflammatory activity [3]. DFMO 13.9\% cream is used to inhibit growth and reduce the amount of facial hair in women. The drug development process of DFMO in these diseases is currently at a relatively early stage, and therefore the full pharmacokinetic characterization in patients, in conjunction with pharmacodynamics (clinical efficacy/safety) is essential for optimization of drug therapy [9].

A number of analytical methods have been reported for measuring DFMO in biological fluids and tissue extracts. These methods involved HPLC techniques [10,11,12]. The HPLC techniques currently available for the quantification of DFMO in biological fluids involve either pre or post column derivatization with UV or fluorescence detection $[13,14]$ and LC carried out by evaporative light scattering detection [15]. Few methods have been reported in the literature for the analysis of DFMO including spectrophotometry $[16,17]$.

Regarding all the above mentioned, we decided to develop a newer HPTLC method suitable for determination of DFMO. The chemical structure of DFMO is presented in (Figure 1).

Since there is no HPTLC analytical method for the determination of DFMO in the pharmaceutical formulations described in the literature. Therefore, the aim 
of this work was to develop and validate such a method that was newer, simple, precise, sensitive, selective, economic, rapid and accurate.<smiles>NCCCC(N)(C(=O)O)C(F)F</smiles>

Figure 1. Chemical structure of eflornithine hydrochloride (MDL 71782A)

In pharmaceutical industry the analysis of pharmaceuticals is an integral and increasingly important part of an overall drug development process. Therefore, rapid and simple methods for routine analysis and quality control of commercial formulations are very desirable. Hence, in the present study, new, simple and selective high performance thin layer chromatography (HPTLC) method for the determination of DFMO drug in commercially available pharmaceutical preparations were developed.

\section{Materials and Methods}

\subsection{Equipment}

The instrument used in the present study was Camag Linnomat V- automatic sample applicator, Camag microliter syringe $(100 \mu \mathrm{l})$, Camag TLC scanner 3, Camag Twin trough chamber of appropriate size, Analytical weighing balance (Shimadzu AX 200), Sonicator (model SONICA 2200MH) were used throughout the experiment. Camag Wincats software was used for acquisition, evaluation and storage of chromatographic data.

\subsection{Reagents and Chemicals}

Reference standard of Eflornithine certified to contain 99.96\% purity and Pharmaceutical preparation: Ornidyl Vial (SVP) $200 \mathrm{mg} / \mathrm{ml}$ of DFMO was received as a gift samples from WINTAC Limited, Bangalore, India. Silica gel (TLC plates) $60 \mathrm{~F}_{254}(10 \mathrm{~cm} \times 10 \mathrm{~cm}$ with $0.2 \mathrm{~mm}$ thickness) were used as stationary phase. All chemicals and reagents used were of analytical grade and obtained from Qualigens. Methanol was from Sigma-Aldrich. Silica gel HPTLC plates $(10 \times 10 \mathrm{~cm})$ were from E. Merck, Germany using a Camag Linomat automatic TLC sampler 5 (Switzerland).

\subsection{Preparation of Solutions}

\subsubsection{Stock and Working Standard Solutions}

A standard stock solution containing $1000 \mathrm{ng} \mathrm{mL}^{-1}$ of DFMO was prepared by dissolving in methanol separately. A working standard solution was prepared separately from the standard stock and further diluted with methanol to obtain the different working standard solutions ranging from 300-800ng $\mathrm{mL}^{-1}$.

\subsubsection{Sample Solutions}

The sample vial (SVP) containing 200mg $\mathrm{mL}^{-1}$. Pipetted out $1 \mathrm{ml}$ and diluted to $100 \mathrm{ml}$ with methanol.
Now further dilutions were done to get the final concentration of $1000 \mathrm{ng} \mathrm{mL} \mathrm{m}^{-1}$. The solutions were sonicated for $30 \mathrm{~min}$ and filtered through $0.45 \mu$ nylon membrane filter. From the filtrate $10 \mathrm{~mL}$ of solution was taken and used for further reading. The proposed HPTLC method was applied and the concentration of each component in both the formulations was determined.

\subsection{Preparation of Calibration Curves}

A methanolic solution of DFMO $(1 \mathrm{mg} / \mathrm{ml})$ was prepared. This solution was further diluted with methanol to yield a solution containing $1 \mu \mathrm{g} \mathrm{mL}^{-1}$. Different concentrations of DFMO in a concentration range of 300$800 \mathrm{ng} / \mathrm{ml}$ were applied on plates as $8 \mathrm{~mm}$ bands, $8 \mathrm{~mm}$ apart and $1 \mathrm{~cm}$ from edge of the plate, by means of Camag Linomat V automatic sample applicator fitted with $100 \mu \mathrm{l}$ Hamilton syringe. A methanol blank was applied to parallel track. The mobile phase consisted of methanol: chloroform: acetic acid: 1\%triethylamine (4:6:0.1:0.5 $\mathrm{v} / \mathrm{v} / \mathrm{v})$. Linear ascending development was carried out in twin trough glass chamber saturated with mobile phase. The optimized chamber saturation time for mobile phase was $20 \mathrm{~min}$ at room temperature. The length of chromatogram run was approximately $80 \mathrm{~mm}$. Subsequent to the development; TLC plate was dried in a current of air with the help of an air-dryer. Densitometric scanning was performed on Camag TLC scanner 3with winCATS software (slit-micro, $6 \times 0.30 \mathrm{~mm}$ ) in the absorbance mode at 220nm for the estimation of DFMO. The source of radiation utilized was deuterium lamp ( $D_{2}$ Lamp) and then the calibration curves were set up by plotting peak area against the drug quantity per spot. The equations of calibration curves were estimated using linear and nonlinear regression analysis and correlation coefficients (r) were calculated. The linear regression data for the calibration plots illustrate a good linear relationship over a concentration range of 300-800ng spot ${ }^{-1}$ for DFMO with respect to the peak area. Each concentration was repeated six times. Area is plotted graphically as a function of analyte concentration (Figure 2). Chromatogram is shown in (Figure 3).

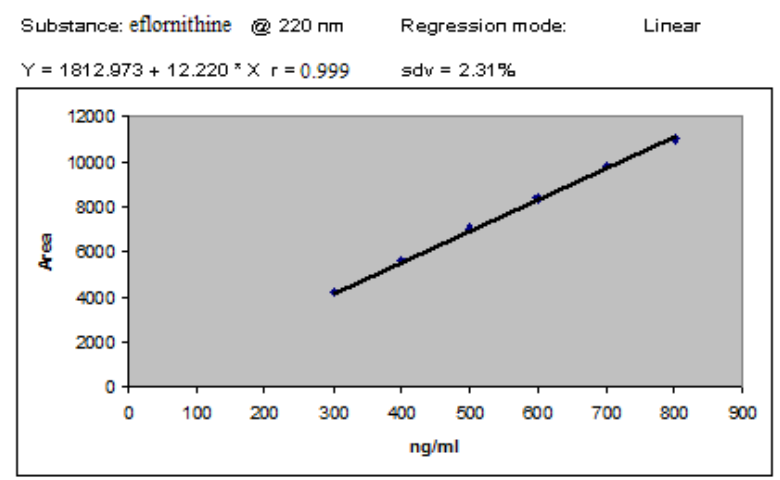

Figure 2. Calibration curve of DFMO at 220nm

\subsection{Method Validation}

\subsubsection{Linearity and Range}

The linear regression data for the calibration plots illustrate a good linear relationship over a concentration range of $300-800 \mathrm{ng}$ spot $^{-1}$ for DFMO with respect to the peak area. From the statistical treatment of the linearity 
data of DFMO, it is clear that the response of DFMO is linear between lower to higher level. Each concentration was repeated six times and obtained information on the variation in peak area response. Area is plotted graphically as a function of analyte concentration (Figure 2). Chromatogram is shown in (Figure 3).



Figure 3. Chromatograms showing linearity of DFMO

\subsubsection{Accuracy}

Accuracy was found out by recovery study from prepared mixture at three levels of standard addition 50\%, $100 \%$ and $150 \%$ by considering 800ng $\mathrm{mL}^{-1}$ concentrations as $100 \%$ for DFMO respectively. Accuracy is often expressed as percentage recovery by the assay of known added amounts of analyte. The accuracy is calculated as the percentage of the analyte response of sample compared to that of a solution containing the analyte at a concentration corresponding to $100.44 \%$ recovery (Table 1$)$.

Table 1. Recovery Study from Synthetic Mixture

\begin{tabular}{|c|c|c|}
\hline \multicolumn{3}{|c|}{ DFMO } \\
\hline $\begin{array}{c}\text { Excess drug added to } \\
\text { analyte (\%) }\end{array}$ & $\begin{array}{c}\text { Conc. } \\
\left(\text { ng mL }{ }^{-1}\right)\end{array}$ & Percentage Recovery \pm RSD \\
\hline 0 & 400 & $98.9049 \pm 0.3226$ \\
\hline $50 \%$ & 600 & $101.654 \pm 0.4956$ \\
\hline $100 \%$ & 800 & $99.5157 \pm 1.64$ \\
\hline $150 \%$ & 1000 & $101.6944 \pm 1.592$ \\
\hline
\end{tabular}

\subsubsection{Precision}

The precision of the analytical method was studied by analysis of multiple sampling of homogeneous sample.

\subsubsection{Method Reproducibility}

Method reproducibility was demonstrated by intraday and inter-day precision measurements of peak area for each title ingredient.

The intraday (within-day in three replicates) and interday precision (for three days) was carried out using three different concentrations (300, 400, 500ng spot ${ }^{-1}$ of DFMO) in five times. The result expressed in terms of percent relative standard deviation (\%R.S.D.). The obtained results within and between days were in acceptable range indicating good precision of the proposed method (Table 2 and Table 3).
Table 2. Precision Study Results (Intraday)

\begin{tabular}{|c|c|c|c|c|}
\hline \multirow{2}{*}{ Intraday } & $\begin{array}{c}\text { Conc. } \\
\text { (ng spot }^{-1} \text { ) }\end{array}$ & Mean area & \%RSD & \%recovery \\
\hline \multirow{3}{*}{ DFMO } & 300 & 4195.333 & 0.947087 & 97.66 \\
\cline { 2 - 5 } & 400 & 5453.233 & 0.815223 & 99.166 \\
\cline { 2 - 5 } & 500 & 6426.367 & 0.23344 & 100.542 \\
\hline
\end{tabular}

Table 3. Precision Study Results (Inter-day)

\begin{tabular}{|c|c|c|c|c|}
\hline $\begin{array}{c}\text { Inter- } \\
\text { day }\end{array}$ & $\begin{array}{c}\text { Conc. } \\
\left.\text { (ng spot }^{-1}\right)\end{array}$ & Mean area & \%RSD & \%recovery \\
\hline \multirow{3}{*}{ DFMO } & 300 & 4391.333 & 0.383665 & 99.60 \\
\cline { 2 - 5 } & 400 & 5503.1 & 0.373295 & 98.89 \\
\cline { 2 - 5 } & 500 & 6570.567 & 1.240529 & 99.23 \\
\hline
\end{tabular}

\subsubsection{Robustness}

By introducing small changes in the mobile phase composition, duration of mobile phase saturation and activation of pre-washed TLC plates with methanol, the effects on the results were examined. Robustness of the method was done in triplicate at concentration level of 800ng spot $^{-1}$ and the \%R.S.D was calculated. The low values of \%R.S.D. indicated the robustness of the method (Table 4).

Table 4. Robustness of the HPTLC Method ( $\mathrm{n}=800 \mathrm{ng}$ spot -1 of DFMO)

\begin{tabular}{|c|c|c|c|c|c|}
\hline \multirow[b]{2}{*}{$\begin{array}{l}\text { Robustne } \\
\text { ss }\end{array}$} & \multicolumn{3}{|c|}{ Wavelength(nm) } & \multicolumn{2}{|c|}{ Mobile Phase } \\
\hline & 208 & 220 & 248 & $\begin{array}{c}\text { 2:6:0.05: } \\
1(\mathrm{v} / \mathrm{v} / \mathrm{v}) \\
:: 1 \\
(\mathrm{v} / \mathrm{v} / \mathrm{v})\end{array}$ & $\begin{array}{c}\text { 1:4:0.05: } \\
0.5(\mathrm{v} / \mathrm{v} / \mathrm{v} \\
)\end{array}$ \\
\hline area & 6456.5 & 4629.6 & 3256.2 & 4394.0 & 5501.1 \\
\hline $\begin{array}{c}\text { \%RS } \\
\text { D }\end{array}$ & 1.371 & 0.4493 & 0.2161 & 0.446914 & 0.98816 \\
\hline
\end{tabular}

\subsubsection{Limit of Detection (LOD) and Limit of Quantification (LOQ)}

Calibration curve was repeated for 6 times and the standard deviation (SD) of the intercepts was calculated. The limit of detection was calculated by $\mathrm{LOD}=3.3 \sigma / S$, 
where $\sigma$ is the standard deviation of the response of the blank or the standard deviation of intercepts of regression lines and $S$ is the slope of the calibration curve. The limit of quantification was calculated by $\mathrm{LOQ}=10 \sigma / S$ under the ICH guidelines [18]. The values of LOD, LOQ and all analytical parameter for the determination of eflornithine hydrochloride are given in (Table 5).

Table 5. Analytical Parameters for the Determination of DFMO Using the Proposed Method

\begin{tabular}{|c|c|}
\hline Parameter & DFMO \\
\hline$\lambda \max (\mathrm{nm})$ & 220 \\
\hline Beer's Law Limit (ng mL $\left.{ }^{-1}\right)$ & $300-800$ \\
\hline \multicolumn{2}{|c|}{ Linear regression equation $\mathrm{A}=\mathrm{mC}+\mathrm{b}$} \\
\hline Slope (m) & 1812.973 \\
\hline Intercept (b) & 12.220 \\
\hline Correlation coefficient (r) & 0.999 \\
\hline LOD (ng mL ${ }^{-1}$ ) & 0.6238 \\
\hline LOQ (ng mL $\left.\mathrm{mL}^{-1}\right)$ & 1.8903 \\
\hline Standard deviation (\%) & 2.31 \\
\hline Percentage Recovery & 100.44 \\
\hline
\end{tabular}

* $\mathrm{A}$ is the absorbance and b concentration in $\mathrm{ng} \mathrm{mL}^{-1}$.



Figure 4. Chromatogram of assay of DFMO

Table 6. Analysis of Commercial Formulation (Ornidyl)

\begin{tabular}{|c|c|c|}
\hline \multicolumn{3}{|c|}{ DFMO } \\
\hline $\begin{array}{l}\text { Conc. Spotted } \\
\quad\left(\text { ng mL }{ }^{-1}\right)\end{array}$ & $\begin{array}{l}\text { Conc. Found } \\
\left(\text { ng } \mu L^{-1}\right)\end{array}$ & Percentage recovery $\pm \% \mathrm{RSD}$ \\
\hline 1000 & 991.919 & $99.1919 \pm 0.67$ \\
\hline
\end{tabular}

\section{Results and Discussion}

The objective of the proposed work was to develop simultaneous methods for the determination of DFMO, and to validate the methods according to USP and ICH guidelines and applying the same for its estimation in marketed formulations. There is no official method for the estimation of DFMO.

In stability indicating HPTLC method, the conditions were optimized to obtain an adequate separation of eluted compounds. Initially, various mobile phase compositions were tried, to separate title ingredients. Mobile phase

\subsection{Analytical Procedure for the Assay of DFMO in Pharmaceutical Formulations}

Applicability of the proposed method was tested by analyzing the commercially available Ornidyl the sample vial (SVP) to containing $200 \mathrm{mg} \mathrm{mL}^{-1}$ of DFMO. The pharmaceutical sample solutions were prepared as described in experimental section. The analysis was repeated in triplicate. Active component was analyzed separately to study the interference of pharmaceutical excipients during estimation.

A single spot at $\mathrm{Rf}=0.55$ was observed when scanned at $220 \mathrm{~nm}$ in the chromatogram of the commercial formulation which was compared with standard mixture. There was no interference from the excipients and the other active components present in the formulation (Figure 4). The values of \% recovery from formulation as shown in the (Table 6) was found to be very close to each other as well as to the label value of commercial pharmaceutical formulation, and is within the limit (label claim $\pm 5 \%$ ) which shows that the method is applicable for determination of DFMO. 
found to be less than $2 \%$. The proposed method was validated in accordance with ICH parameters and the applied for analysis of the same in marketed formulations.

The major advantage of HPTLC was that several samples can be run simultaneously using a small quantity of mobile phase unlike HPLC, thus lowering analysis time and cost per analysis. Suspensions, dirty or turbid samples can be directly applied. It facilitates automated application and scanning in situ. HPTLC facilitates repeated detection (scanning) of the chromatogram with the same or different parameters. The aim of this work was to develop an accurate, specific, repeatable method for the determination of DFMO per ICH guidelines. Initially methanol: chloroform: acetic acid: triethylamine in varying ratios were tried. Finally, the mobile phase consisting of methanol: chloroform: acetic acid: 1\% triethylamine (4:6:0.1:0.5 v/v/v) gave a sharp and well-defined peak at $\mathrm{R}_{\mathrm{f}}$ value of 0.55 for DFMO (Figure 5).Well-defined spots were obtained when the chamber was saturated with mobile phase for $20 \mathrm{~min}$ at room temperature.

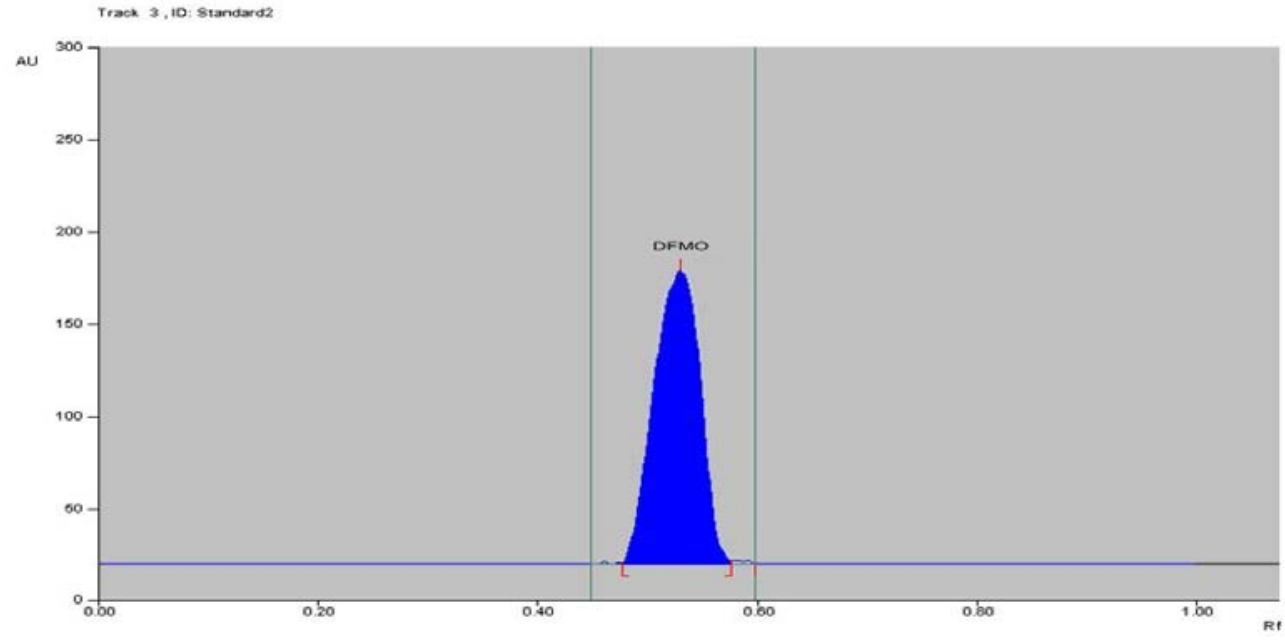

Figure 5. Representative densitogram of DFMO $\mathrm{R}_{\mathrm{f}} 0.55$ respectively

\section{Conclusion}

The developed HPTLC technique was found a precise, specific, accurate and robust for the simultaneous determination of DFMO. Statistical analysis proves that the method was reproducible and selective for the analysis of title ingredients. Since the proposed mobile phase effectively resolves DFMO the method can be used for qualitative as well as quantitative analysis of DFMO in commercial formulations as well as in laboratory prepared mixtures.

\section{Acknowledgements}

This study is a part of Ph.D. research work of Mr. Amit Kumar, registered in IFTM University, Moradabad 244102 India, which is done at NKBR College of Pharmacy \& Research Centre, Meerut, Uttar Pradesh, India. We thank Mr. S.P.Venkatesh Prasad, PEC College of Pharmacy, Bangalore, India, for his support and Wintac Ltd, Bangalore, India, for providing a sample of DFMO as a gift.

\section{Competing Interests}

NONE

\section{Abbreviations}

UV, ultra-violet; HPTLC, high-performance thin layer chromatography.

\section{References}

[1] Bacchi, C. J., Goldberg, B., Carofalo-Hannan, J., Rattendi, D., Lyte, P. and Yarlett, N, "In vivo effects of $\alpha$-DLDifluoromethylornithine on the metabolism and morphology of Trypanosoma brucei brucei,” J. Biochem., 309. 737-40. 1995.

[2] Bitonti, A. J., Bacchi, C. J., McCann, P. P. and Sipertsma, A, "Intestinal changes caused by DL- $\alpha$-difluoromethylornithine (DFMO), an inhibitor of ornithine decarboxylase," Biochem. Pharmacol., 34. 1773-78. 1985.

[3] McCann, P. P., Bbacchi, C. J. and Clarkson, A. B, "In vivo effects of $\alpha$-DL-Difluoromethyl ornithine on the metabolism and morphology of Trypanosoma brucei,” Med. Biol., 59. 434-37. 1981.

[4] Sjoerdsma, A, "Treatment of gambiense sleeping sickness in the Sudan with oral DFMO (DL- $\alpha$-difluoromethylornithine), an inhibitor of ornithine decarboxylase," Clin. Pharmacol. Ther., 30. 3-8. 1981.

[5] Sjoerdsma, A. and Schechter, P, "Difiuoromethylornithine in the treatment of African trypanosomiasis," Clin. Pharmacol. Ther., 35. 287-90. 1984.

[6] Available:

http://www.accessdata.fda.gov/scripts/cder/drugsatfda/index.cfm?f useaction=Search.SearchAction\&SearchType=BasicSearch\&searc h Term=eflornithine\&Search_Button=Submit. [April 18, 1986].

[7] Pepin, J., Guern, C., Milord, F. and Schechter, P. J, "Difluoromethylornithine for arseno-resistant trypanosoma brucei gambiense sleeping sickness,” The Lancet, 330. 1431-1433. 1987.

[8] Merali, S. and Clarkson, A. B. Jr, "Polyamine content of Pneumocystis carinii and response to the ornithine decarboxylase inhibitor DL-alpha-difluoromethylornithine," Antimicrob. Agents Chemother., 40. 973-978. 1996.

[9] Balfour, J. A. and McClellan, K, “Topical eflornithine,” Am. J. Clin. Dermatol, 2(3). 197-201.

[10] Cohen, J. L., Ko, R. J., Lo, A. T., Shields, M. D. and Gilman, T. M, "High-pressure liquid chromatographic analysis of eflornithine in serum,” J. Pharm. Sci., 78(2). 114-6. Feb. 1989.

[11] Huebert, N. D., Schwartz, J. J. and Haegele, K. D, “ Analysis of 2difluoromethyl-DL-ornithine in human plasma, cerebrospinal fluid 
and urine by cation-exchange high-performance liquid chromatography,” J. Chromatogr. A., 762(1-2). 293-8. Feb. 1997.

[12] Saravanan, C., Kumudhavalli, M. V., Kumar, M. and Jayakar, B, “ A new validated RP-HPLC method for estimation of eflornithine hydrochloride in tablet dosage form,” J. Phar. Res., 2. 1730-1731. 2009.

[13] Kilkenny, M. L., Slavik, M., Christopher, M. R. and Stobaugh, J. F, "Plasma analysis of alpha-difluoromethylornithine using precolumn derivatization with naphthalene-2,3-dicarboxaldehyde/CN and multidimensional chromatography,” J. Pharm. Biomed. Anal., 17. 1205-1213. 1998.

[14] Jansson-Löfmark, R., Römsing, S., Albers, E. and Ashton, M, "Determination of eflornithine enantiomers in plasma by precolumn derivatization with $O$-phthalaldehyde- $N$-acetyl-Lcysteine and liquid chromatography with UV detection,” Biomed. Chromatogr., 24(7). 768-773. July 2010.
[15] Malm, M. and Bergqvist, Y, "Determination of eflornithine enantiomers in plasma, by solid-phase extraction and liquid chromatography with evaporative light-scattering detection," $J$. Chromatogr. B. Analyt. Technol. Biomed. Life Sci., 846. 98-104. 2007.

[16] Kumar, A., Venkatesh, Prasad, S. P., Mohan, S. and Kumar, P, "Spectrophotometric determination of eflornithine hydrochloride as active pharmaceutical ingredient using sodium 1,2naphthoquinone-4-sulfonate as the derivative chromogenic reagent,” Trade Sci. Inc., 7, 2008.

[17] Kumar, A., Venkatesh, Prasad, S. P., Mohan, S. and Singh, A. K, "Estimation of eflornithine hydrochloride by UV spectroscopy," Trade Sci. Inc., 8. 2009.

[18] Validation of Analytical Procedures, Methodology ICH Harmonised Tripartite Guideline, Having Reached Step 4 of the ICH Process at the ICH Steering Committee meeting on November 6, 1996. 